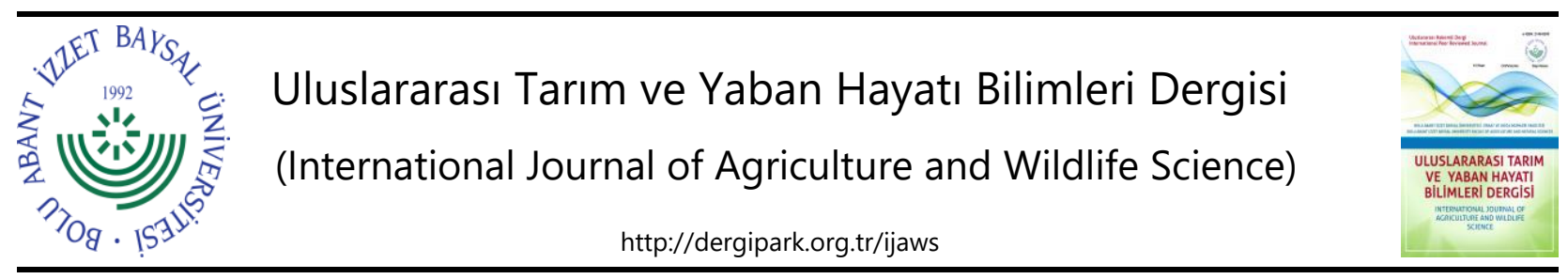

Araştırma Makalesi

\title{
Germencik (Aydın) iliçesinde Yetiştirilen Sarılop İncirlerinde (Ficus carica L.) Klon Seleksiyonu
}

\author{
Serkan Uzun* (iD)，Tarık Yarılgaç \\ Ordu Üniversitesi, Ziraat Fakültesi, Bahçe Bitkileri Bölümü, Ordu \\ Geliş tarihi (Received): 04.06.2020 Kabul tarihi (Accepted): 14.12.2020
}

\begin{abstract}
Anahtar kelimeler:
Sarılop, genetik kaynaklar, klon seleksiyonu, meyve özellikleri

*Sorumlu yazar

serkan.uzun28@hotmail.com

Özet. Bu çalışma Aydın ili Germencik ilçesinde yetişen Sarılop incir çeşidinde meyve ağırığı yüksek olan ve taze tüketim açısından üstün özellikler taşıyan klonların tespit edilmesi amacıyla yürütülmüştür. Çalışmada 40 farklı klon meyve ağırığı, meyve boyutları, ostiol genişliği, suda çözünebilir kuru madde miktarı, titre edilebilir asitlik gibi fiziksel ölçümlerin yanı sıra meyve şekli, meyve simetrisi, kabuk çatlaması, meyve uç şekli, kabuğun soyulma durumu, lentisel miktarı, ostiol çatlamalarına dayanıklıık gibi kalitatif özellikler bakımından incelenmiştir. Araştırma bulgularında meyve ağırlı̆ı 15.2-78.4 g, ostiol genişliği 1.1-13.1 mm, suda çözünebilir kuru madde miktarı \%15.829.8 ve titre edilebilir asitlik miktarı \%0.151-0.646 arasında tespit edilmiştir. Bununla birlikte incelenen klonların \%82'sinde meyve şekli 'küresel', \%60'ında ise meyve simetrisi 'var' olarak gözlemlenmiştir. Araştırma sonucunda meyve ağırlığı, meyve şekli, boyun uzunluğu, kabuk çatlaması, kabuğun soyulma durumu, ostiol genişliği ve suda çözünebilir kuru madde miktarı özellikleri dikkate alınarak yapılan tartılı derecelendirme neticesinde 830 ve üzerinde puan alan 09 GS 25 ve 09 GS 31 klonları ümitvar olarak seçilmiştir. Ayrıca ilçenin Sarılop incir genetik kaynakları bakımından kıymetli materyallere sahip olduğu kanaatine varılmıştır.
\end{abstract}

\section{Clonal Selection in Sarılop Figs (Ficus carica L.) Grown in Germencik (Aydın) District}

\section{Keywords:}

Sarılop, genetic resources, clone selection, fruit characteristics

\begin{abstract}
This study was carried out to determine the clones with high fruit weight and superior features in terms of fresh consumption in the Sarılop fig cultivar grown in Germencik district of Aydın. In the study, 40 different clones were examined in terms of fruit characteristics such as fruit weight, fruit sizes, ostiol width, soluble solids content, titratable acidity. In addition, qualitative traits such as fruit shape, fruit symmetry, crust cracking, fruit shape, peeling of the skin, lenticel amount, resistance to ostiol cracking were also examined. In the research findings, fruit weight was 15.2-78.4 g, ostiol width was $1.1-13.1 \mathrm{~mm}$, soluble solids content was $15.8-29.8 \%$ and titratable acidity was $0.151-0.646 \%$. Also, the fruits belonging to the examined clones, the fruit shape was observed as "global" in $82 \%$ and the fruit symmetry was observed as "present" in 60\%. In the research, 09 GS 25 and 09 GS 31 clones scoring 830 and above were selected as promising as a result of weighted ranking performed to the characteristics of fruit weight, fruit shape, neck length, shell cracking, peeling of the skin, ostiol width, and soluble solids content. In addition, it was concluded that the district has valuable materials in terms of Sarılop fig genetic resources.
\end{abstract}




\section{GiRiş}

Dünya üzerinde yetiştiriciliği yapılan en eski meyve ağaçlarından biri olan incir (Ficus carica L.) Moraceae familyasının Ficus cinsine dahildir (Abdelsalam ve ark., 2019). Kültür tarihi ilk insanlara kadar dayanan bu tür subtropik iklimin yaşandığı çoğu yerde yetişmekle birlikte dünya üretiminin büyük bir çoğunluğu Akdeniz havzasından elde edilmektedir (Condit, 1941; Bostan ve ark., 1998; Sadder ve Ateyyeh, 2006).

Sofralık ve kurutularak tüketilmeye uygun olan çok sayıda çeşidi bulunan incir zengin besin içeriği ve insan sağlığı üzerine olumlu etkileri nedeniyle dünya çapında oldukça popüler bir meyvedir (Viuda-Martos ve ark., 2015). Meyveleri kuru veya taze olarak tüketilebildiği gibi reçel, şurup ve alkollü içeceklerin üretiminde de kullanılmaktadır (Aljane ve ark., 2008). Dünya incir üretimi 2018 yılı itibariyle 301.062 ha alanda 1.135 .316 ton olup en fazla üretim alanına sahip ülkeler sırasıyla Fas (61.498 ha), Türkiye (51.389 ha) ve Cezayir (39.356 ha)'dir. Üretim bakımından Türkiye 306.499 ton ile ilk sırada yer alırken ardından 189.339 ton ile Mısır ve 128.380 ton ile Fas gelmektedir (FAO, 2020).

Üretim miktarı bakımından incirde dünya lideri olan ülkemiz aynı zamanda bu türün anavatan sınırları içerisinde yer almakta, özellikle iklim ve toprak koşullarına iyi uyum sağlaması nedeniyle de pek çok farklı yerel tür ve çeşide ev sahipliği yapmaktadır (Aksoy ve ark., 2001; Aksu Uslu ve ark., 2018). Bu durum açıkça göstermektedir ki ülkemizde korunması ve değerlendirilmesi gereken büyük bir genetik zenginlik bulunmaktadır. Bu amaca yönelik olarak ülkemizin farklı bölgelerinde pek çok seleksiyon çalışması yürütülmüştür (Aksoy ve ark., 1992; Ilgın, 1995; Özkaya, 1997; Aksoy ve ark., 2003; Polat ve Özkaya, 2005; Şimşek, 2008; Gözlekci, 2010; Karadeniz ve Bak., 2016; Aksu Uslu ve ark., 2018). İncirde geleneksel ıslah çalışmaları özellikle verim, meyve kalitesi, biyotik ve abiyotik stres koşullarına dayanıkılık gibi özellikleri temel almaktadır. Bunun yanı sıra tozlanma sorunlarının giderilmesi, meyvede olgunluk ve dayanıkııık, çevresel koşullara tolerans gibi özellikler de ıslah çalışmalarına konu edilmektedir (Mars, 2003; Aljane ve ark., 2018). Sofralık incirlerde ise meyve ağırlığı, meyve iriliği, boyun uzunluğu, ostiol açıklığı pH, asitlik ve suda çözünebilir kuru madde miktarı gibi özellikler kalite kriteri olarak dikkate alınan başııca özellikler arasında yer almaktadır (Göçmez ve Seferoğlu, 2014).

Çalışmaya konu olan Sarılop inciri dünya pazarlarında yüksek talep gören, çoğunlukla kurutmalık özellikleriyle ön plana çıkan ve ülkemizde yetiştiriciliğinin de çoğunlukla bu amaca yönelik olarak gerçekleştirildiği önemli bir çeşidimizdir. Ancak sahip olduğu özellikler itibariyle bu çeşit az miktarlarda da olsa taze tüketime yönelik olarak pazarda kendine yer bulmaktadır (Aksoy ve ark., 2014). Dolayısıyla bu çalışmada Germencik (Aydın) ilçesinde yetişen Sarılop incir çeşidinde taze tüketime yönelik olarak üstün özellikler taşıyan ve meyve ağırlığı yüksek olan klonların belirlenmesi amaçlanmıştır.

\section{MATERYAL VE METOT}

Bu çalışma 2007 yılında Aydın ili Germencik ilçesi ve bağlı mahallelerinde yürütülmüştür. Çalışmanın bitkisel materyalini yörede yetiştirilen Sarılop incir çeşidine ait klonlar oluşturmuştur. Yapılan arazi gezilerinde meyve iriliği, ostiol açıklığı, tat ve meyve çatlaması gibi özellikler dikkate alınarak 40 klon belirlenerek işaretlenmiştir. İsaretlenen klonlardan meyve özelliklerinin belirlenmesi amacıyla, her klonda meyvelerin yeme olgunluğuna eriştiği, meyve kabuğunun parlak ve çeşide özgü sarı rengini aldığı dönemde 20'şer adet meyve örneği ağacın tamamını temsil edecek şekilde tesadüfi olarak hasat edilmiştir. Hasat işlemleri 20 Ağustos ile 5 Eylül tarihleri arasında tamamlanmıştır.

Hasat edilen meyvelerde fiziksel, kimyasal ölçümler yapılmış ve bazı kalitatif özellikler değerlendirilmiştir. Bu ölçümler Uluslararası Bitki Genetik Kaynakları Enstitüsü (International Plant Genetic Resources Institute, IPGRI) formatına uygun şekilde gerçekleştirilmiştir. Buna göre meyvelerde incelenen kalitatif özellikler ve bu özelliklere ait sınıflar Çizelge 1'de sunulmuştur (IPGRI ve CIHEAM, 2003). Sınıflarda yer alan gruplar rakamsal kodlamalarla ifade edilerek bulguların hazırlanmasında bu kodlar kullanılmıştır.

Çalışmada fiziksel ölçümlerden meyve ağırlığı 20 adet meyvenin $0.1 \mathrm{~g}$ hassasiyetindeki dijital hassas terazi ile tartılması, meyve genişliği, meyve boyu, ostiol genişliği, boyun uzunluğu, sap uzunluğu ve meyve et kalınlığı 20 adet meyvenin $0.01 \mathrm{~mm}$ 'ye duyarlı dijital kumpas ile ölçülmesiyle belirlenmiştir. Meyve uzunluğunun meyve genişliğine oranlanması ile boy/genişlik oranı saptanmıştır. Suda çözünebilir kuru madde miktarı (SÇKM) meyve suyunda el refraktometresi kullanılarak tespit edilmiştir. Titre edilebilir asitlik içeriği (TA) meyve suyunun saf su ile seyreltilmesinden sonra (10:40) belirlenerek sitrik asit cinsinden hesaplanmıştır. Yapılan ölçüm ve değerlendirmelerin ardından üstün nitelikli klonların ortaya çıkarılması amacıyla Çalışkan ve Polat (2008), tarafından daha önce uygulanmış tartılı derecelendirme yönteminde bazı değişiklikler yapılmıştır (Çizelge 2). 
Çizelge 1. Sarılop incir klonlarında incelenen kalitatif özellikler ve sınıflandırılmaları (IPGRI ve CIHEAM, 2003). Table 1. Qualitative properties and classifications investigated in Sarllop fig clones.

\begin{tabular}{llll}
\hline No & Özellik & Kısaltma & Sınıflar \\
\hline 1 & Meyve şekli & MŞ & 1: Dikdörtgen *(I<0.9), 2: Küresel (I=0.9-1.1), 3: Kutupları yassılaşmış (I>1.1) \\
2 & Meyve uç şekli & UŞ & 1: Düz, 2: Yuvarlak, 3: Sivri \\
3 & Kabuk zemin rengi & KR & 1: Siyah, 2: Mor, Kahverengi, 3: Yeşil, Açık yeşil, 4: Sarı yeşil, 5: Sarı \\
4 & Kabuk çatlaması & KÇ & 1: Çatlamış, 2: Seyrek, 3: Önemsiz \\
5 & Meyve simetrisi & MS & 1: Var, 2: Yok \\
6 & Damarlılık & D & 1: Yok, 2: Orta, 3: Belirgin \\
7 & Kabuğun soyulma durumu & SD & 1: Kolay, 2: Orta, 3: Zor \\
8 & Çekirdek miktarı & ÇM & 1: Yok, 2: Az, 3: Orta, 4: Çok \\
9 & Meyve eti iç rengi & MER & 1: Beyaz, 2: Kehribar, 3: Pembe, 4: Kırmızı, 5: Koyu kırmızı \\
10 & Meyve eti tadı & T & 1: Nötr, 2: Hafif tatlı, 3: Aromatik, 4: Belirgin \\
11 & Meyve eti sululuğu & MES & 1: Hamurumsu, 2: Hafif sulu, 3: Sulu, 4: Çok sulu \\
12 & Lentisel miktarı & LM & 1: Seyrek, 2: Orta, 3: Çok \\
13 & Lentisel rengi & LR & 1: Beyaz, 2: Pembe, 3: Yeşil \\
14 & İç boşluğu & iB & 1: Yok, 2: Çok küçük, 3: Küçük, 4: Orta, Geniş \\
15 & Ostiol çatlamalarına dayanıklılık & OÇD & 1: Hassas, 2: Orta, 3: Dayanıklı \\
16 & Sap şekli & SŞ & 1: Farklı genişliklerde, 2: Uzun ve ince, 3: Kısa ve kalın \\
17 & Saptan ayrılma durumu & SAD & 1: Kolay, 2: Zor \\
\hline
\end{tabular}

*I: Uzunluk/Genişlik oranı.

Çizelge 2. Sarılop incir klonlarında kullanılan tartılı derecelendirme özellikleri ve puanlama sistemi (Çalışkan ve Polat, 2008). Table 2. Weighted ranking traits and scoring system used in Sarlop fig clones.

\begin{tabular}{|c|c|c|c|}
\hline Özellik & Katsayı & Sınıf Aralığı & Puanlar \\
\hline \multirow{6}{*}{ Meyve ağırlığı (g) } & \multirow{6}{*}{30} & $\leq 25.7$ & 0 \\
\hline & & $25.8-36.3$ & 2 \\
\hline & & $36.4-46.8$ & 4 \\
\hline & & $46.9-57.3$ & 6 \\
\hline & & $57.4-67.9$ & 8 \\
\hline & & $\geq 68.0$ & 10 \\
\hline \multirow{3}{*}{ Meyve şekli } & \multirow{3}{*}{10} & $\leq 0.9$ & 8 \\
\hline & & $1.0-1.1$ & 10 \\
\hline & & $\geq 1.2$ & 6 \\
\hline \multirow{4}{*}{ Boyun uzunluğu (mm) } & \multirow{4}{*}{10} & $\leq 8.4$ & 0 \\
\hline & & $8.5-14.7$ & 10 \\
\hline & & $14.8-20.9$ & 6 \\
\hline & & $\geq 21.0$ & 2 \\
\hline \multirow{3}{*}{ Kabuk çatlaması } & \multirow{3}{*}{10} & Önemsiz & 10 \\
\hline & & Seyrek & 6 \\
\hline & & Çatlak & 0 \\
\hline \multirow{3}{*}{ Kabuğun soyulma durumu } & \multirow{3}{*}{10} & Kolay & 10 \\
\hline & & Orta & 6 \\
\hline & & Zor & 0 \\
\hline \multirow{4}{*}{ Ostiol genişliği (mm) } & \multirow{4}{*}{15} & $\leq 4.1$ & 10 \\
\hline & & $4.2-7.1$ & 8 \\
\hline & & $7.2-10.1$ & 6 \\
\hline & & $\geq 10.2$ & 2 \\
\hline \multirow{5}{*}{ SÇKM (\%) } & \multirow{5}{*}{15} & $\leq 18.6$ & 2 \\
\hline & & $18.7-21.4$ & 10 \\
\hline & & $21.5-24.2$ & 8 \\
\hline & & $24.3-27.0$ & 6 \\
\hline & & $\geq 27.1$ & 4 \\
\hline Toplam & 100 & & \\
\hline
\end{tabular}

\section{BULGULAR VE TARTIŞMA}

Sarılop klonları, çalışmada incelenen meyve özellikleri bakımından büyük farklılıklar göstermiştir (Çizelge 3). Klonlar arasında en büyük varyasyon titre edilebilir asitlik (\%82.88), boyun uzunluğu (\%61.50), sap uzunluğu (\%51.30), ostiol genişliği (\%49.95), meyve ağılığı (\%37.03) ve meyve eti kalınlığında (\%34.44) tespit edilmiştir. En düşük varyasyon gösteren özellik ise meyve eni (\%15.38) olmuştur.

Meyve ağırlığı taze tüketim açısından incir meyvesinin pazar kalitesini doğrudan etkileyen önemli bir ticari özelliktir (Aksoy ve ark., 1992; Pereira ve ark., 2017). Çalışmada belirlenen en düşük meyve ağırlığı $15.2 \mathrm{~g}$ ile 09 GS 09 klonunda, en yüksek ise 78.4 g ile 09 GS 06 klonunda tespit edilmiştir (Çizelge 3). Daha önce Sarılop çeşidi üzerinde yapılan çalışmalarda meyve ağırlığı Kaynak ve ark. (1999), 43.1 g, Aksoy ve ark. (2001), 64.77-67.84 g; 
Çatmadım (2014), 41.42-51.25 g, Ersoy ve ark. (2018), 43.11 g; Özkul (2019), $73.80 \mathrm{~g}$ olarak bildirilmiştir. Çalışmamızda meyve ağırlığı bakımından elde edilen bulguların geniş bir değer aralığına sahip olduğu görülmekle birlikte literatürde bulunan çalışmaların sonuçları bu aralık içerisinde yer almıştır. Ancak çalışmamızda 09 GS 06 (78.4 g), 09 GS 02 (66.5 g), 09 GS 08 (65.2 g), 09 GS 12 (62.7 g), 09 GS 17 (62.4 g) ve 09 GS 19 (60.5 g) klonları Kaynak ve ark. (1999), Çatmadım (2014), Ersoy ve ark. (2018) tarafından bildirilen değerlerden daha yüksek meyve ağırlıklarıyla dikkat çekmektedir.

Çizelge 3. Sarılop incir klonlarında ölçülen meyve özellikleri.

Table 3. Fruit characteristics of Sarlop fig clones.

\begin{tabular}{|c|c|c|c|c|c|c|c|c|c|c|}
\hline Klon & $\begin{array}{l}\text { MA } \\
\text { (g) }\end{array}$ & $\begin{array}{l}\text { MG } \\
(\mathrm{mm})\end{array}$ & $\begin{array}{l}\text { MB } \\
(\mathrm{mm})\end{array}$ & Mi & $\begin{array}{l}\text { OG } \\
(\mathrm{mm})\end{array}$ & $\begin{array}{l}\text { BU } \\
(\mathrm{mm})\end{array}$ & $\begin{array}{l}\text { SU } \\
(\mathrm{mm})\end{array}$ & $\begin{array}{l}\text { MEK } \\
(\mathrm{mm})\end{array}$ & $\begin{array}{l}\text { SÇKM } \\
\text { (\%) }\end{array}$ & $\begin{array}{l}\text { TA } \\
(\%)\end{array}$ \\
\hline 09 GS 01 & 45.6 & 49.0 & 41.2 & 0.8 & 2.8 & 7.9 & 11.9 & 2.6 & 22.0 & 0.363 \\
\hline 09 GS 02 & 66.5 & 54.0 & 47.8 & 0.9 & 6.0 & 8.4 & 4.8 & 3.4 & 15.8 & 0.363 \\
\hline 09 GS 03 & 50.5 & 44.9 & 53.9 & 1.1 & 5.1 & 13.2 & 10.7 & 2.9 & 17.1 & 0.276 \\
\hline 09 GS 04 & 21.0 & 36.6 & 42.5 & 1.2 & 2.7 & 9.0 & 6.3 & 1.7 & 18.4 & 0.366 \\
\hline 09 GS 05 & 28.0 & 38.1 & 36.5 & 1.0 & 7.0 & 6.0 & 9.3 & 2.4 & 26.8 & 0.646 \\
\hline 09 GS 06 & 78.4 & 56.8 & 43.9 & 0.8 & 4.2 & 2.2 & 2.3 & 2.2 & 22.0 & 0.210 \\
\hline 09 GS 07 & 38.3 & 43.2 & 35.6 & 0.8 & 4.9 & 4.4 & 2.5 & 3.2 & 24.9 & 0.231 \\
\hline 09 GS 08 & 65.2 & 54.8 & 47.1 & 0.9 & 4.4 & 6.0 & 8.5 & 3.1 & 17.3 & 0.253 \\
\hline 09 GS 09 & 15.2 & 33.0 & 25.5 & 0.8 & 4.1 & 4.1 & 9.6 & 1.8 & 23.5 & 0.287 \\
\hline 09 GS 10 & 27.3 & 37.0 & 38.6 & 1.0 & 3.1 & 6.6 & 7.8 & 2.7 & 27.3 & 0.155 \\
\hline 09 GS 11 & 37.3 & 42.4 & 53.5 & 1.3 & 7.2 & 22.3 & 4.2 & 3.6 & 27.3 & 0.155 \\
\hline 09 GS 12 & 62.7 & 52.8 & 65.2 & 1.2 & 6.6 & 27.1 & 5.9 & 6.6 & 19.6 & 0.323 \\
\hline 09 GS 13 & 51.8 & 49.3 & 61.8 & 1.3 & 13.1 & 19.9 & 4.5 & 2.7 & 18.2 & 0.480 \\
\hline 09 GS 14 & 28.0 & 37.7 & 31.9 & 0.8 & 1.7 & 2.9 & 5.7 & 2.7 & 25.2 & 0.642 \\
\hline 09 GS 15 & 47.3 & 45.9 & 44.4 & 1.0 & 5.5 & 10.0 & 11.9 & 2.9 & 22.0 & 0.411 \\
\hline 09 GS 16 & 48.5 & 50.6 & 32.8 & 0.6 & 9.2 & 7.6 & 6.6 & 3.2 & 18.2 & 0.437 \\
\hline 09 GS 17 & 62.4 & 51.1 & 44.8 & 0.9 & 6.6 & 6.0 & 5.9 & 3.1 & 19.2 & 0.267 \\
\hline 09 GS 18 & 35.7 & 43.1 & 41.9 & 1.0 & 6.7 & 5.5 & 2.6 & 2.0 & 25.0 & 0.325 \\
\hline 09 GS 19 & 60.5 & 54.7 & 50.5 & 0.9 & 4.1 & 10.9 & 4.1 & 3.3 & 18.2 & 0.387 \\
\hline 09 GS 20 & 44.8 & 43.6 & 46.1 & 1.1 & 5.5 & 10.8 & 7.6 & 4.1 & 21.2 & 0.151 \\
\hline 09 GS 21 & 27.8 & 37.0 & 41.0 & 1.1 & 3.8 & 10.9 & 11.9 & 2.8 & 22.3 & 0.358 \\
\hline 09 GS 22 & 39.7 & 43.7 & 46.0 & 1.1 & 3.2 & 12.0 & 2.8 & 1.8 & 20.1 & 0.210 \\
\hline 09 GS 23 & 29.1 & 37.9 & 49.6 & 1.3 & 4.8 & 15.2 & 5.0 & 2.9 & 28.2 & 0.158 \\
\hline 09 GS 24 & 40.0 & 48.3 & 46.7 & 1.0 & 2.4 & 14.0 & 9.4 & 2.4 & 17.3 & 0.302 \\
\hline 09 GS 25 & 48.1 & 48.9 & 45.5 & 0.9 & 3.1 & 10.4 & 3.7 & 3.5 & 22.3 & 0.311 \\
\hline 09 GS 26 & 27.8 & 37.8 & 39.9 & 1.1 & 3.3 & 6.9 & 8.7 & 2.7 & 25.2 & 0.032 \\
\hline 09 GS 27 & 23.1 & 35.5 & 37.6 & 1.1 & 2.7 & 9.2 & 5.7 & 2.5 & 28.5 & 0.039 \\
\hline 09 GS 28 & 30.1 & 39.9 & 40.6 & 1.0 & 2.2 & 6.7 & 6.6 & 2.2 & 26.2 & 0.036 \\
\hline 09 GS 29 & 43.6 & 49.8 & 40.2 & 0.8 & 1.1 & 6.0 & 3.8 & 3.3 & 22.5 & 0.027 \\
\hline 09 GS 30 & 42.2 & 55.4 & 40.0 & 0.7 & 3.7 & 3.4 & 3.6 & 4.6 & 26.2 & 0.023 \\
\hline 09 GS 31 & 75.0 & 56.5 & 49.2 & 0.9 & 5.0 & 13.9 & 13.7 & 4.5 & 19.8 & 0.024 \\
\hline 09 GS 32 & 40.3 & 44.6 & 38.1 & 0.9 & 4.1 & 5.2 & 3.6 & 2.8 & 25.3 & 0.047 \\
\hline 09 GS 33 & 24.0 & 41.9 & 29.0 & 0.7 & 2.9 & 3.2 & 3.7 & 1.5 & 29.8 & 0.025 \\
\hline 09 GS 34 & 35.5 & 39.1 & 36.8 & 0.9 & 2.7 & 8.9 & 5.2 & 1.7 & 28.0 & 0.033 \\
\hline 09 GS 35 & 44.4 & 45.2 & 37.6 & 0.8 & 3.0 & 5.3 & 9.0 & 2.7 & 22.3 & 0.028 \\
\hline 09 GS 36 & 33.5 & 42.1 & 32.4 & 0.8 & 4.1 & 5.8 & 5.2 & 1.4 & 23.5 & 0.049 \\
\hline 09 GS 37 & 48.6 & 44.6 & 39.6 & 0.9 & 4.3 & 5.1 & 2.8 & 2.4 & 24.7 & 0.020 \\
\hline 09 GS 38 & 29.1 & 36.9 & 36.5 & 1.0 & 3.6 & 11.5 & 3.1 & 2.0 & 28.8 & 0.017 \\
\hline 09 GS 39 & 50.0 & 50.9 & 43.7 & 0.9 & 4.0 & 4.1 & 0.0 & 2.7 & 23.0 & 0.037 \\
\hline 09 GS 40 & 17.8 & 32.8 & 29.0 & 0.9 & 2.2 & 2.5 & 7.4 & 1.8 & 25.7 & 0.030 \\
\hline Ortalama & 41.62 & 44.69 & 42.1 & 1.0 & 4.4 & 8.8 & 6.2 & 2.8 & 23.0 & 0.213 \\
\hline Minimum & 15.20 & 32.80 & 25.5 & 0.6 & 1.1 & 2.2 & 0.0 & 1.4 & 15.8 & 0.017 \\
\hline Maksimum & 78.40 & 56.80 & 65.2 & 1.3 & 13.1 & 27.1 & 13.7 & 6.6 & 29.8 & 0.646 \\
\hline VK (\%) & 37.03 & 15.38 & 19.52 & 17.58 & 49.95 & 61.50 & 51.30 & 34.44 & 16.52 & 82.88 \\
\hline
\end{tabular}

MA: Meyve ağırlığı, MG: Meyve genişliği, MB: Meyve boyu, Mi: Meyve indeksi, OG: Ostiol genişliği, BU: Boyun uzunluğu, SU: Sap uzunluğu, MEK: Meyve eti kalınlığı, SÇKM: Suda çözünebilir kuru madde miktarı, TA: Titre edilebilir asitlik miktarı, VK: Varyasyon katsayısı.

Meyve ağırığının yanı sıra meyvenin genişliği ve iriliği de ürünün pazarda yüksek fiyattan alıcı bulmasında oldukça önemli özelliklerdir (Pereira ve ark., 2017). Meyve iriliğinin tüketici tercihlerini etkilediği, küçük meyvelerin çoğunlukla konservelik kullanımda, iri meyvelerin ise taze tüketim amacıyla tercih edildiği bilinmektedir (Hssaini ve ark., 2020). Nitekim meyve çapı $4 \mathrm{~cm}$ üzerinde olan orta ve iri meyveli incirlerin taze tüketime yönelik olarak değerlendirilebileceği bildirilmektedir (Göçmez ve Seferoğlu, 2014). Çalışmadan elde edilen en yüksek meyve genişlikleri sırasıyla 56.8 mm (09 GS 06), 56.5 mm (09 GS 31) ve 55.4 mm (09 GS 30) olurken en düşük meyve genişliği ise 32.8 mm (09 GS 40) olarak belirlenmiştir (Çizelge 3). Meyve boyu ise $25.5 \mathrm{~mm}$ (09 GS 09)-65.2 mm 
(09 GS 12) arasında değişiklik göstermiştir (Çizelge 3). Klonlarda hesaplanan genişlik/uzunluk oranı ise 0.6 mm (09 GS 16)-1.3 mm (09 GS 11, 09 GS 13, 09 GS 23) arasındadır (Çizelge 3). Sarılop incirlerinde Kaynak ve ark. (1999), meyve genişliğini $50.95 \mathrm{~mm}$, meyve boyunu 46.34 mm; Çatmadım (2014), meyve genişliğini 44.00-50.64 mm, meyve boyu 30.54-38.60 mm; Ersoy ve ark. (2018), meyve genişliği 41.06 mm, meyve boyu 46.23 mm, şekil indeksi 0.90 ve Özkul (2019), meyve genişliği 55.87 mm, meyve boyu $39.80 \mathrm{~mm}$ olarak tespit etmişlerdir. Çalışmada incelenen klonların meyve genişliği ve boyu literatürde yer alan çalışmalarla benzerlikler taşımakla birlikte daha iri ve daha küçük boyutlu meyveler olduğu da görünmektedir. Ancak popülasyonda genel olarak orta ve iri meyveli klonlar bulunmakta ve bu klonların taze tüketime yönelik olarak değerlendirilebileceği düşünülmektedir.

Ostiol genişliğinin çok fazla olması böceklerin meyve içerisine girişini kolaylaştırarak hastalıkla bulaşma riskini artırdığından istenmeyen bir özelliktir (Doyle ve ark., 2003). Çalışmada ostiol genişlikleri 1.1 mm (09 GS 29)-13.1 mm (09 GS 13) arasında değişiklik göstermiştir (Çizelge 3). Bununla birlikte 09 GS 29 (1.1 mm), 09GS 14 (1.7 mm), 09 GS 40 (2.2 mm), 09 GS 28 (2.2 mm), 09 GS $24(2.4 \mathrm{~mm}), 09$ GS $04(2.7 \mathrm{~mm}), 09$ GS $34(2.7 \mathrm{~mm}), 09 \mathrm{GS} 27(2.7$ $\mathrm{mm}), 09 \mathrm{GS} 01(2.8 \mathrm{~mm}), 09 \mathrm{GS} 33(2.9 \mathrm{~mm}), 09 \mathrm{GS} 35(3.0 \mathrm{~mm})$ klonları $3.0 \mathrm{~mm}$ ve altında ostiol genişlikleriyle dikkat çekmektedir. Sarılop incirlerinde ostiol genişliğini daha önce yürütülen çalışmalarda Aksoy ve ark. (2001), 6.03-6.09; Ersoy ve ark. (2018), 3.70 mm; Özkul (2019), 6.84 mm olarak bildirmişlerdir. Çalışmada incelenen klonlara ait meyvelerde belirlenen ostiol genişliklerinin genel olarak düşük olduğu söylenebilir.

Çizelge 4. Sarılop incir klonlarının kalitatif özellikler bakımından yer aldıkları sınıflar*.

Table 4. The classes of the Sarlop fig clones in terms of qualitative properties.

\begin{tabular}{|c|c|c|c|c|c|c|c|c|c|c|c|c|c|c|c|c|c|}
\hline Klon & MŞ & UŞ & MS & SŞ & SAD & SD & D & KÇ & OÇD & KR & LM & LR & MER & $\mathbf{T}$ & MES & iB & ÇM \\
\hline 09 GS 01 & 2 & 1 & 1 & 2 & 1 & 1 & 2 & 3 & 3 & 4 & 1 & 1 & 4 & 2 & 2 & 3 & 4 \\
\hline 09 GS 02 & 2 & 1 & 1 & 3 & 2 & 1 & 3 & 3 & 3 & 5 & 2 & 1 & 3 & 3 & 2 & 1 & 3 \\
\hline 09 GS 03 & 2 & 1 & 2 & 2 & 1 & 2 & 2 & 2 & 1 & 6 & 2 & 3 & 4 & 4 & 3 & 1 & 3 \\
\hline 09 GS 04 & 3 & 1 & 2 & 2 & 1 & 1 & 2 & 3 & 3 & 5 & 1 & 2 & 5 & 1 & 2 & 2 & 4 \\
\hline 09 GS 05 & 2 & 1 & 2 & 1 & 1 & 1 & 3 & 3 & 1 & 4 & 1 & 1 & 4 & 2 & 2 & 4 & 4 \\
\hline 09 GS 06 & 2 & 1 & 1 & 3 & 1 & 2 & 2 & 2 & 2 & 4 & 2 & 1 & 1 & 2 & 3 & 1 & 3 \\
\hline 09 GS 07 & 2 & 1 & 1 & 3 & 2 & 2 & 1 & 3 & 3 & 6 & 1 & 1 & 4 & 2 & 2 & 1 & 2 \\
\hline 09 GS 08 & 2 & 1 & 2 & 3 & 1 & 2 & 2 & 3 & 3 & 4 & 3 & 1 & 1 & 2 & 2 & 1 & 3 \\
\hline 09 GS 09 & 3 & 3 & 2 & 2 & 1 & 2 & 2 & 3 & 3 & 5 & 3 & 1 & 5 & 2 & 2 & 2 & 4 \\
\hline 09 GS 10 & 2 & 1 & 2 & 2 & 1 & 1 & 2 & 3 & 3 & 6 & 1 & 1 & 2 & 4 & 3 & 1 & 3 \\
\hline 09 GS 11 & 2 & 1 & 2 & 3 & 1 & 2 & 3 & 2 & 2 & 4 & 2 & 1 & 4 & 3 & 2 & 2 & 3 \\
\hline 09 GS 12 & 1 & 1 & 2 & 3 & 2 & 1 & 3 & 3 & 3 & 4 & 2 & 1 & 4 & 2 & 1 & 4 & 3 \\
\hline 09 GS 13 & 2 & 1 & 2 & 2 & 1 & 1 & 3 & 2 & 3 & 5 & 2 & 1 & 4 & 4 & 2 & 4 & 3 \\
\hline 09 GS 14 & 1 & 1 & 2 & 1 & 2 & 2 & 3 & 3 & 3 & 5 & 1 & 1 & 2 & 3 & 3 & 4 & 2 \\
\hline 09 GS 15 & 2 & 1 & 2 & 2 & 1 & 2 & 3 & 2 & 3 & 4 & 2 & 1 & 4 & 3 & 2 & 3 & 4 \\
\hline 09 GS 16 & 2 & 1 & 2 & 3 & 1 & 1 & 3 & 3 & 2 & 4 & 2 & 1 & 2 & 2 & 2 & 5 & 4 \\
\hline 09 GS 17 & 3 & 1 & 2 & 3 & 1 & 1 & 3 & 3 & 3 & 4 & 1 & 1 & 3 & 3 & 2 & 4 & 3 \\
\hline 09 GS 18 & 2 & 2 & 2 & 1 & 1 & 2 & 2 & 2 & 1 & 4 & 2 & 1 & 4 & 2 & 4 & 3 & 4 \\
\hline 09 GS 19 & 2 & 1 & 1 & 3 & 1 & 1 & 3 & 3 & 2 & 4 & 2 & 1 & 3 & 2 & 1 & 3 & 3 \\
\hline 09 GS 20 & 2 & 2 & 1 & 3 & 1 & 1 & 3 & 3 & 3 & 4 & 2 & 1 & 4 & 2 & 2 & 3 & 3 \\
\hline 09 GS 21 & 2 & 1 & 1 & 1 & 1 & 1 & 2 & 3 & 3 & 4 & 2 & 1 & 2 & 3 & 1 & 2 & 4 \\
\hline 09 GS 22 & 2 & 1 & 1 & 3 & 2 & 3 & 3 & 1 & 1 & 6 & 2 & 3 & 4 & 4 & 3 & 1 & 4 \\
\hline 09 GS 23 & 2 & 1 & 1 & 3 & 1 & 2 & 3 & 3 & 3 & 4 & 2 & 2 & 2 & 2 & 2 & 1 & 3 \\
\hline 09 GS 24 & 2 & 1 & 2 & 3 & 1 & 1 & 3 & 3 & 3 & 5 & 1 & 1 & 4 & 4 & 2 & 2 & 3 \\
\hline 09 GS 25 & 2 & 1 & 2 & 3 & 2 & 1 & 2 & 3 & 3 & 6 & 1 & 3 & 2 & 3 & 3 & 1 & 2 \\
\hline 09 GS 26 & 2 & 1 & 1 & 3 & 2 & 1 & 3 & 3 & 3 & 4 & 2 & 1 & 3 & 3 & 3 & 1 & 3 \\
\hline 09 GS 27 & 1 & 1 & 1 & 3 & 1 & 2 & 3 & 3 & 3 & 4 & 2 & 1 & 3 & 2 & 3 & 2 & 3 \\
\hline 09 GS 28 & 2 & 1 & 1 & 3 & 1 & 2 & 3 & 3 & 3 & 4 & 1 & 1 & 4 & 3 & 2 & 3 & 3 \\
\hline 09 GS 29 & 2 & 1 & 1 & 3 & 1 & 2 & 3 & 3 & 3 & 4 & 1 & 1 & 2 & 2 & 2 & 4 & 3 \\
\hline 09 GS 30 & 2 & 1 & 1 & 3 & 2 & 2 & 1 & 3 & 2 & 6 & 2 & 1 & 2 & 4 & 3 & 1 & 2 \\
\hline 09 GS 31 & 2 & 1 & 1 & 2 & 2 & 1 & 1 & 3 & 2 & 6 & 3 & 1 & 2 & 3 & 3 & 1 & 2 \\
\hline 09 GS 32 & 2 & 1 & 1 & 3 & 2 & 2 & 2 & 2 & 3 & 4 & 1 & 1 & 4 & 2 & 2 & 2 & 3 \\
\hline 09 GS 33 & 3 & 1 & 1 & 3 & 1 & 1 & 2 & 3 & 3 & 4 & 2 & 2 & 5 & 2 & 2 & 2 & 2 \\
\hline 09 GS 34 & 2 & 1 & 1 & 1 & 1 & 2 & 3 & 3 & 3 & 5 & 2 & 1 & 4 & 2 & 2 & 4 & 3 \\
\hline 09 GS 35 & 3 & 1 & 1 & 3 & 1 & 1 & 2 & 3 & 3 & 4 & 2 & 1 & 4 & 2 & 2 & 1 & 2 \\
\hline 09 GS 36 & 2 & 1 & 1 & 3 & 1 & 2 & 1 & 3 & 2 & 6 & 1 & 1 & 4 & 2 & 2 & 1 & 3 \\
\hline 09 GS 37 & 2 & 1 & 1 & 3 & 2 & 2 & 3 & 3 & 3 & 4 & 1 & 1 & 2 & 2 & 2 & 1 & 3 \\
\hline 09 GS 38 & 2 & 1 & 1 & 3 & 1 & 1 & 2 & 3 & 1 & 4 & 2 & 1 & 4 & 3 & 2 & 1 & 2 \\
\hline 09 GS 39 & 2 & 1 & 1 & 3 & 2 & 1 & 1 & 3 & 3 & 4 & 1 & 1 & 4 & 2 & 3 & 1 & 3 \\
\hline 09 GS 40 & 2 & 1 & 1 & 3 & 1 & 1 & 1 & 3 & 3 & 4 & 1 & 1 & 2 & 2 & 2 & 1 & 2 \\
\hline
\end{tabular}

*Sınıflamalarda kullanılan kodların açılımlarına çalışmanın metot bölümünde yer verilmiştir.

Klonlarda belirlenen SÇKM içerikleri \%15.8 (09 GS 02)-\%29.8 (09 GS 33) arasında, TA içeriği ise \%0.151 (09 GS 20)-\%0.646 (09 GS 05) arasında tespit edilmiştir (Çizelge 3). Sarılop incirlerinde daha önce Kaynak ve ark. (1999), 
\%18.04, TA \%0.23; Aksoy ve ark. (2001), SÇKM \%20.00-23.00 TA \%0.134-0.138; Çatmadım (2014), SÇKM \%6.5019.63, TA \%0.141-0.241; Ersoy ve ark. (2018), SÇKM \%20.57, TA \%0.15; Özkul (2019), SÇKM içeriği \%21.38, TA \%0.831 olarak rapor etmişlerdir. Bu değerler çalışmamızdan elde edilen bulgularla benzerlikler taşımaktadır.

Çalışma süresince klonlarda belirlenen kalitatif özellikler Çizelge 4' de gösterilmiştir. İncirde paketleme ve nakliye açısından meyve şekli oldukça önem bir özelliktir (Çalışkan ve Polat, 2008). Küresel meyveler bu konuda önemli bir avantaj sağlamaktadır (Condit, 1941). Buna göre araştırmaya dahil edilen klonların \%82'sinin meyve şekli 'küresel', \%60'ında meye simetrisi 'var', olarak belirlenmiştir. Ayrıca incelenen meyvelerin \%52.5'inde kabuğun soyulma durumu 'kolay', \%80'inde kabuk çatlamaları 'önemsiz' ve \% 70'i ostiol çatlamalarına 'dayanıklı' olarak değerlendirilmiştir (Çizelge 4).

Çalışmadan elde edilen bulgular doğrultusunda meyve ağırlığı, meyve şekli, boyun uzunluğu, kabuk çatlaması, kabuğun soyulma durumu, ostiol genişliği ve suda çözünebilir kuru madde miktarı özellikleri dikkate alınarak yapılan tartılı derecelendirme sonucunda klonların aldıkları puanlar Çizelge 5'de sunulmuştur. Buna göre 09 GS 11 klonu 470 ile en düşük, 09 GS 31 klonu ise 950 ile en yüksek ise puan alan klonlar olmuşlardır.

Çizelge 5. Sarılop incir klonlarının tartılı derecelendirme sonuçları.

Table 5. Results of weighted ranking for Sarlop fig clones.

\begin{tabular}{|c|c|c|c|c|c|c|c|c|}
\hline Klon & MA & MŞ & BU & KÇ & KSD & OG & SÇKM & TP \\
\hline 09 GS 01 & 120 & 80 & 0 & 100 & 100 & 150 & 120 & 670 \\
\hline 09 GS 02 & 240 & 80 & 0 & 100 & 100 & 120 & 30 & 670 \\
\hline 09 GS 03 & 180 & 100 & 100 & 60 & 60 & 120 & 30 & 650 \\
\hline 09 GS 04 & 0 & 60 & 100 & 100 & 100 & 150 & 30 & 540 \\
\hline 09 GS 05 & 60 & 100 & 0 & 100 & 100 & 120 & 90 & 570 \\
\hline 09 GS 06 & 300 & 80 & 0 & 60 & 60 & 120 & 120 & 740 \\
\hline 09 GS 07 & 120 & 80 & 0 & 100 & 60 & 120 & 90 & 570 \\
\hline 09 GS 08 & 240 & 80 & 0 & 100 & 60 & 120 & 30 & 630 \\
\hline 09 GS 09 & 0 & 80 & 0 & 100 & 60 & 150 & 120 & 510 \\
\hline 09 GS 10 & 60 & 100 & 0 & 100 & 100 & 150 & 60 & 570 \\
\hline 09 GS 11 & 120 & 60 & 20 & 60 & 60 & 90 & 60 & 470 \\
\hline 09 GS 12 & 240 & 60 & 20 & 100 & 100 & 120 & 150 & 790 \\
\hline 09 GS 13 & 180 & 60 & 60 & 60 & 100 & 30 & 30 & 520 \\
\hline 09 GS 14 & 60 & 80 & 0 & 100 & 60 & 150 & 90 & 540 \\
\hline 09 GS 15 & 180 & 100 & 100 & 60 & 60 & 120 & 120 & 740 \\
\hline 09 GS 16 & 180 & 80 & 0 & 100 & 100 & 90 & 30 & 580 \\
\hline 09 GS 17 & 240 & 80 & 0 & 100 & 100 & 120 & 150 & 790 \\
\hline 09 GS 18 & 60 & 100 & 0 & 60 & 60 & 120 & 90 & 490 \\
\hline 09 GS 19 & 240 & 80 & 100 & 100 & 100 & 150 & 30 & 800 \\
\hline 09 GS 20 & 120 & 100 & 100 & 100 & 100 & 120 & 150 & 790 \\
\hline 09 GS 21 & 60 & 100 & 100 & 100 & 100 & 150 & 120 & 730 \\
\hline 09 GS 22 & 120 & 100 & 100 & 0 & 0 & 150 & 150 & 620 \\
\hline 09 GS 23 & 60 & 60 & 60 & 100 & 60 & 120 & 60 & 520 \\
\hline 09 GS 24 & 120 & 100 & 100 & 100 & 100 & 150 & 30 & 700 \\
\hline 09 GS 25 & 180 & 80 & 100 & 100 & 100 & 150 & 120 & 830 \\
\hline 09 GS 26 & 60 & 100 & 0 & 100 & 100 & 150 & 90 & 600 \\
\hline 09 GS 27 & 0 & 100 & 100 & 100 & 60 & 150 & 60 & 570 \\
\hline 09 GS 28 & 60 & 100 & 0 & 100 & 60 & 150 & 90 & 560 \\
\hline 09 GS 29 & 120 & 80 & 0 & 100 & 60 & 150 & 120 & 630 \\
\hline 09 GS 30 & 120 & 80 & 0 & 100 & 60 & 150 & 90 & 600 \\
\hline 09 GS 31 & 300 & 80 & 100 & 100 & 100 & 120 & 150 & 950 \\
\hline 09 GS 32 & 120 & 80 & 0 & 60 & 60 & 150 & 90 & 560 \\
\hline 09 GS 33 & 0 & 80 & 0 & 100 & 100 & 150 & 60 & 490 \\
\hline 09 GS 34 & 60 & 80 & 100 & 100 & 60 & 150 & 60 & 610 \\
\hline 09 GS 35 & 120 & 80 & 0 & 100 & 100 & 150 & 120 & 670 \\
\hline 09 GS 36 & 60 & 80 & 0 & 100 & 60 & 150 & 120 & 570 \\
\hline 09 GS 37 & 180 & 80 & 0 & 100 & 60 & 120 & 90 & 630 \\
\hline 09 GS 38 & 60 & 100 & 100 & 100 & 100 & 150 & 60 & 670 \\
\hline 09 GS 39 & 180 & 80 & 0 & 100 & 100 & 150 & 120 & 730 \\
\hline 09 GS 40 & 0 & 80 & 0 & 100 & 100 & 150 & 90 & 520 \\
\hline
\end{tabular}

MA: Meyve ağırlığı, MŞ: Meyve şekli, BU: Boyun uzunluğu, KÇ: Kabuk çatlaması, KSD: Kabuğun soyulma durumu, OG: Ostiol genişliği, SÇKM: Suda çözünebilir kuru madde miktarı, TA: Titre edilebilir asitlik miktarı, TP: Toplam puan.

\section{SONUÇ}

Çalışmada incelenen klonlar arasında meyve özellikleri bakımından geniş bir varyasyon olduğu görülmüştür. Tartılı derecelendirme sonucu 830 ve üzerinde puan alan 09 GS 25 ve 09 GS 31 klonları ümitvar olarak seçilmiştir. 
Bunun yanı sıra pazar tercihini etkileyen önemli bir ticari kriter olan meyve ağırlığı bakımından $60 \mathrm{~g}$ üzerinde değerlere sahip olan 09 GS 02, 09 GS 06, 09 GS 08, 09 GS 12, 09 GS 17, 09 GS 19 klonları ile ostiol açıklığı 2.0 mm' den az olan 09 GS 14, 09 GS 29 klonları bu özellikleriyle ön plana çıkmıştır. Çalışmadan elde edilen veriler Germencik ilçesinde yetişen Sarılop incirlerinin birçok önemli ıslah kriteri açısından üstün nitelikler taşıdığını göstermiş ve yörenin genetik olarak zengin bir Sarılop incir popülasyonuna sahip olduğunu ortaya çıkarmıştır. Bu nedenle klonların ileride yapılması muhtemel ıslah çalışmalarında genetik materyal olarak değerlendirilme potansiyeline sahip oldukları düşünülmektedir. Yine de incelenen özellikler üzerine çevresel etmenlerin ve kültürel uygulamaların da etki edebileceği göz önüne alınarak, çalışmanın sonraki aşamasında klonlar arasındaki farklııkların tam olarak ortaya çıkarılabilmesi adına moleküler düzeyde akrabalık ilişkilerinin belirlenmesi önem arz etmektedir.

\section{ÇIKAR ÇATIŞMASI}

Yazarlar arasında herhangi bir çıkar çatışması bulunmamaktadır.

\section{YAZAR KATKISI}

Birinci yazar verilerin analizi ve çalışmanın yazımı, ikinci yazar çalışmanın planlanması ve yürütülmesine katkı sunmuştur.

\section{KAYNAKLAR}

Abdelsalam, N. R., Awad, R. M., Ali, H. M., Salem, M. Z., Latif, K. F. A., \& Elshikh, M. S. (2019). Morphological, pomological, and specific molecular marker resources for genetic diversity analyses in fig (Ficus carica L.). HortScience, 54(8), $1299-1309$.

Aksoy, U., Seferoglu, G., Misirli, A., Kara, S., Sahin, N., Bulbul, S., \& Duzbastilar, M. (1992). Ege Bölgesi koşullarına uygun sofralık incir çeşit seleksiyonu. I. Ulusal Bahçe Bitkileri Kongresi, Ege Üniversitesi Ziraat Fakültesi, İzmir.

Aksoy, U., Can, H. Z., Hepaksoy, S., \& Şahin, N. (2001). Incir Yetiştiriciliği. TüBiTAK TARP (Türkiye Tarımsal Araştırma Projesi) Yayınları, İzmir.

Aksoy, U., Can, H. Z., Misirli, A., \& Kara, S. (2003). Fig (Ficus carica L.) selection study for fresh market in western Turkey. Acta Horticulturae, 605, 197-203.

Aksoy, U., Şen, F., Özer, K. B., \& Can, H. Z. (2014). İncir. Bahçe Haber, 3(1), 10-14.

Aksu Uslu, N., Aydın, E., Er, E., \& Özcan, M. (2018). Sinop ili incir seleksiyonu. International Journal of Agricultural and Natural Sciences, 1(2), 146-149.

Aljane, F., Ferchichi, A., \& Boukhris, M. (2008). Pomological characteristics of local fig (Ficus carica) cultivars in Southern Tunisia. Acta Horticulturae, 798, 123-128.

Aljane F., Essid A., \& Nahdi S. (2018). Improvement of fig (Ficus carica L.) by conventional breeding and biotechnology. In J. Al-Khayri, S. Jain \& D. Johnson (Eds.), Advances in Plant Breeding Strategies: Fruits (pp. 343-375). Springer.

Bostan, S. Z., Islam, A., \& Aygün, A. (1998). A study on pomological characteristics of local fig cultivars in Northern Turkey. Acta Horticulturae, 480, 71-74.

Condit, I. (1941). Fig characteristics useful in the identification of varieties. Hilgardia, 14(1), 1-69.

Çalişkan, O., \& Polat, A. A. (2008). Fruit characteristics of fig cultivars and genotypes grown in Turkey. Scientia Horticulturae, 115(4), 360-367.

Çatmadım, G. (2014). Aydın ili Kuyucak ilçesinde (Büyük Menderes Ovası) yetiştirilen Sarılop ve Bursa Siyahı incir çeşitlerinde meyve gelişimlerinin belirlenmesi. Yüksek Lisans Tezi, Ordu Üniversitesi, Fen Bilimleri Enstitüsü, Ordu.

Doyle, J., Ferguson, L., Herman, K., López Corrales, M., \& Bernalte García, M. J. (2003). Fig cultivar development and evaluation. Acta Horticulturae, 605, 29-32.

Ersoy, N., Gozlekci, S., Gok, V., \& Yilmaz, S. (2018). Fig (Ficus carica L.) fruit: Some physical and chemical properties. Acta Horticulturae, 1173, 329-334.

FAO. (2020). Bitkisel üretim istatistikleri. http://www.fao.org/faostat/en/\#home. Erişim tarihi: 16 Mayıs 2020.

Gozlekci, S. (2010). Selection studies on fig (Ficus carica L.) in Antalya province of Turkey. African Journal of Biotechnology, 9(46), 7857-7862. 
Göçmez, A., \& Seferoğlu, H. G. (2014). Sofralık ve kurutmalık incir kalite kriterleri ve kaliteyi etkileyen faktörler. Türkiye Tarımsal Araştırmalar Dergisi, 1(1), 98-108.

Hssaini, L., Hanine, H., Razouk, R., Ennahli, S., Mekaoui, A., Ejjilani, A., \& Charafi, J. (2020). Assessment of genetic diversity in Moroccan fig (Ficus carica L.) collection by combining morphological and physicochemical descriptors. Genetic Resources and Crop Evolution, 67(2), 457-474.

Ilgın, M. (1995). Kahramanmaraş Bölgesi'nde incir seleksiyonu ve selekte edilen bazı önemli tiplerin meyve doğuşları ve döllenme biyolojileri üzerinde çalışmalar. Doktora Tezi, Çukurova Üniversitesi, Fen Bilimleri Enstitüsü, Adana.

IPGRI ve CIHEAM. (2003). Descriptors for fig. International Plant Genetic Resources Institute, Rome, Italy, and International Centre for Advanced Mediterranean Agronomic Studies, Paris, France.

Karadeniz, T., \& Bak, T. (2016). Clonal selection in Siyah cultivars at Black Sea Region of Turkey. Journal of Hygienic Engineering and Design, 14, 66-68.

Kaynak, L., Gözlekçi, S., \& Ersoy, N. (1999). A research on storage and pomological properties of some fig (Ficus carica L.) cultivars grown in Antalya conditions. Acta Horticulturae, 480, 277-282.

Mars, M. (2003). Fig (Ficus carica L.) genetic resources and breeding. Acta Horticulturae, 605, 19-27.

Ozkaya, M. (1997). Selection studies on fig genotypes grown in Antakya region. MSc. Thesis, Mustafa Kemal University, Hatay.

Özkul, M. (2019). Sarılop incir çeşidinde farlı göz yoğunluğunda kış budama uygulamalarının verim ve kalite üzerine etkileri. Yüksek Lisans Tezi, Kahramanmaraş Sütçü İmam Üniversitesi, Fen Bilimleri Enstitüsü, Kahramanmaraş.

Pereira, C., Sánchez, M. J. S., Gragera, F. P., González, A. M., Rivera, M. C. V., \& Corrales, M. L. (2017). Evaluation of agronomic and fruit quality traits of fig tree varieties (Ficus carica L.) grown in Mediterranean conditions. Spanish Journal of Agricultural Research, 15(3).

Polat, A. A., \& Ozkaya, M. (2005). Selection studies on fig in the Mediterranean region of Turkey. Pakistan Journal of Botany, 37(3), 567.

Sadder, M. T., \& Ateyyeh, A. F. (2006). Molecular assessment of polymorphism among local Jordanian genotypes of the common fig (Ficus carica L.). Scientia Horticulturae, 107(4), 347-351.

Şimşek, M. (2008). Diyarbakır koşullarında incir genetik materyalinin seleksiyonu ve tanımlanması. Doktora Tezi, Çukurova Üniversitesi, Fen Bilimleri Enstitüsü, Adana.

Viuda-Martos, M., Barber, X., Pérez-Álvarez, J. A., \& Fernández-López, J. (2015). Assessment of chemical, physico-chemical, techno-functional and antioxidant properties of fig (Ficus carica L.) powder co-products. Industrial Crops and Products, 69, 472-479. 